\title{
The International Conference on Regional Climate - CORDEX 2016
}

Iréne Lakea ${ }^{a^{*}}$,Hyun-Suk Kang ${ }^{\mathrm{b}}$, Fredolin Tangang ${ }^{\mathrm{c}}$, William J. Gutowskid, Boram Lee ${ }^{\mathrm{e}}$ and Erik Kjellströma ${ }^{\mathrm{a}}$

a Swedish Meteorological and Hydrological Institution, Folkborgsvägen 17, 60176 Norrköping, Sweden

b National Institute of Meteorological Sciences, Korea Meteorological Administration 33 Seohobuk-ro, Seogwipo, Jeju 63568, Korea

The National University of Malaysia, 43600 Bangi, Selangor, Malaysia

d Iowa State University, 3021 Agronomy, Ames, Iowa 50011, USA

e World Climate Research Programme, World Meteorological Organization, 7bis Avenue de la Paix, CH-1211 Geneva, Switzerland

* Corresponding author. Email: irene.lake@smhi.se

\section{ABSTRACT}

The project, which facilitated the attendance, interaction, and training of early-career scientists from developing nations in the Asia-Pacific region at the International Conference on Regional Climate - CORDEX 2016 (ICRC-CORDEX 2016) was a great success. The conference, held in Stockholm, Sweden 17-20 May 2016, was jointly organized by the Swedish Meteorological and Hydrological Institution and the World Climate Research Programme (WCRP). About 90 participants, 46 of whom were from the Asia-Pacific region, were supported financially to attend the conference. The project provided Asia-Pacific region scientists with the opportunity to attend the conference and interact with the $300+$ scientists from 38 nations. Participation via web streaming and Twitter made it possible for the community at large to participate and interact remotely with the conference and its participants. ICRC-CORDEX 2016 offered a platform for further capacity development, training and knowledge exchange for developing nation scientists together with the opportunity to expand existing or build new, collaborations. The conference emphasized the added value, vulnerability, impact and assessment issues, as well as the use and future of regional climate information and CORDEX results as well as the CORDEX goal to build the capacity of regional climate science in developing and transition nations.

\section{KEYWORDS}

Added Value, CORDEX, Impact and Adaptation, International Conference on Regional Climate, Vulnerability

DOI

https://doi.org/10.30852/sb.2017.192

\section{DATES}

Received: 29 May 2017

Published (online): 22 November 2017

Published (PDF): 11 April 2018

\section{INTRODUCTION}

\subsection{CORDEX Background}

Policy and decision makers need information about climate, climate change and impact and vulnerability assessments at the right scales and communicated in an understandable way to ensure that the knowledge is used effectively for adaptation, mitigation and risk management. The understanding of the response of regional and local climate systems to global climate and the influence of the regional and local systems on the global system is the focus of the Coordinated Regional Climate Downscaling Experiment (CORDEX) community. To predict

\section{HGHLIGHTS}

^APN-funded early-career scientists were active participants at the conference

» CORDEX-2016 supported APN goals of enhancing regional cooperation and capacity.

» CORDEX-2016 promoted APN cooperation with other global change and networks.

» CORDEX is substantively advancing climate science for societal needs.

future changes and analyze past changes and trends, earth-system/climate system models are primary tools. Since global scale models are too coarse to resolve 
the questions that decision makers encounter daily, advanced downscaling methods are required to translate this coarse global scale information into finer and more adapted regional and local information.

The World Climate Research Programme (WCRP) initiated the worldwide effort, CORDEX, in 2009 to address these issues. CORDEX compliments the corresponding CMIP global scale effort that aims at supporting climate assessments such as those undertaken by IPCC, and advancing global climate simulations.

\subsection{ICRC-CORDEX 2016}

The International Conference on Regional ClimateCORDEX 2016, held in Stockholm, Sweden 17-20 May 2016, was jointly organized by the Swedish Meteorological and Hydrological Institution (SMHI) and the World Climate Research Programme (WCRP), and attracted over 300 participants from 38 countries. The attendance of about 90 participants was made possible through the financial support from conference sponsors such as APN. For the community at large, remote participation and interaction with the conference and its audience were made possible via web streaming. Twitter question and answer sessions were also available.

The conference offered a platform for scientists, policymakers and the full spectrum of potential end-users of climate information from around the world to interact with the CORDEX research communities from all continents and thus to discuss and develop research on high resolution climate information and its applications to vulnerability, impacts and adaptation (VIA) at the appropriate regional and local scales. It laid the ground for enhanced cooperation and exchange. The participation of early-career scientists from around the world and particularly from developing nations is key to the future success of fostering capacity development, training and knowledge exchange and offering an opportunity to expand or build new collaborations.

\section{METHODOLOGY}

WCRP, SMHI and CORDEX continuously work with capacity building on multiple scales and are engaged in training the next generation of climate experts. For this reason, the conference had a special focus on the active participation of students and early-career scientists, many of whom are active in regions highly vulnerable to

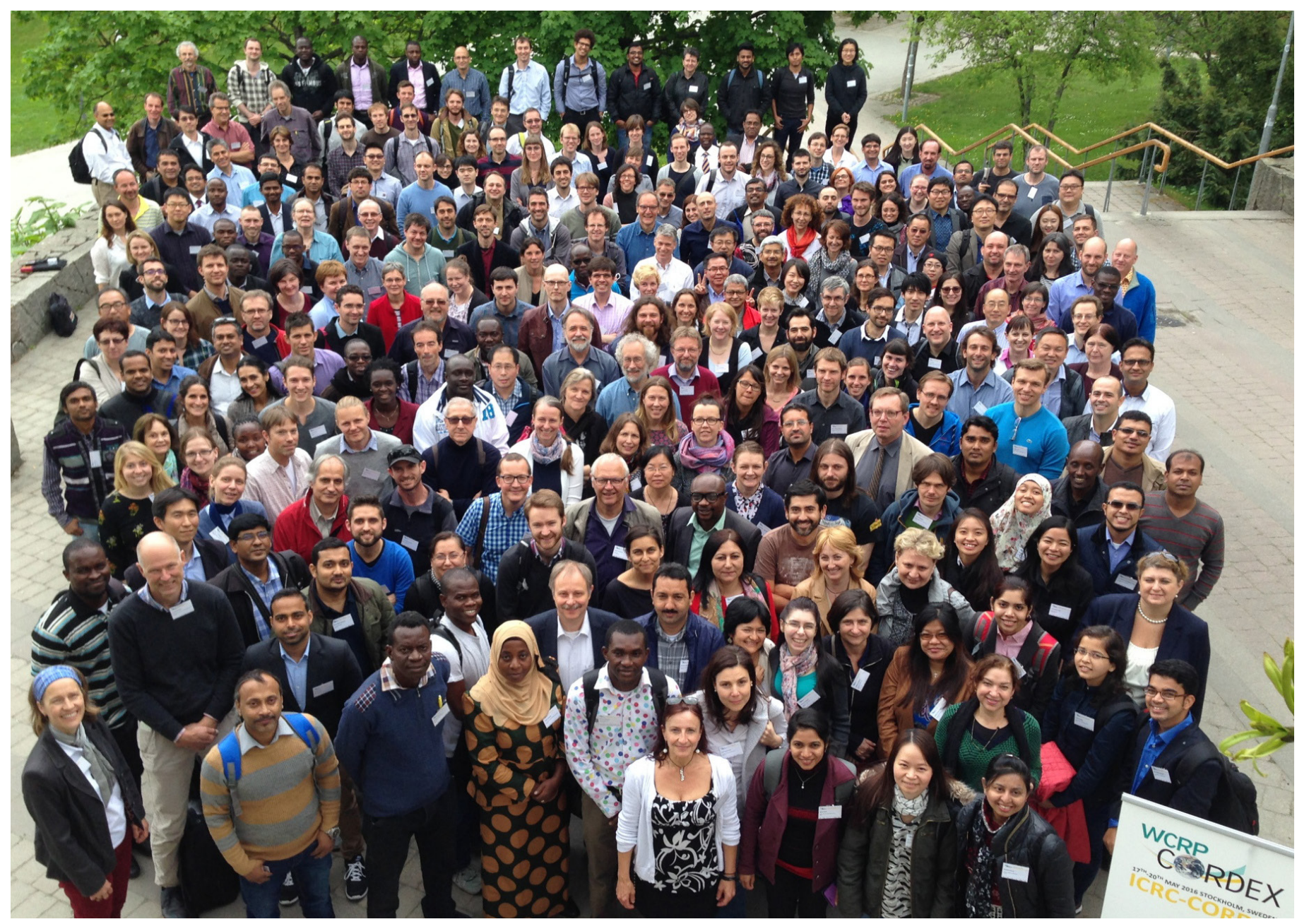

CORDEX2016 GROUP photo 
climate change and variability.

To ensure worldwide representation in this major international climate conference, much effort was put into fundraising for travel support. WCRP, SMHI, APN and other conference sponsors joined their efforts in providing support for aspiring early-career scientists and students to attend the conference, which served as a forum for them to initiate new partnerships in their research/education and to gain insight into the challenges of regional climate science and applications on early-career scientists. Scientific content and presentation skills of authors/speakers provided the basis for judgment. A group of independent judges chosen from the conference participants and with the appropriate scientific expertise performed the evaluation. The best posters were identified and recognized at the final summary plenary session. The three award winners out of the 48 that entered the competition received a "Best Poster Award" certificate and a complimentary handmade glass bowl.

"During my poster presentation, I got an opportunity to seek

suggestions on improvement of my work design as well as through discussions, exchange knowledge and ideas to design further part of my work."

- Anubhav Choudhary, participant

\section{"I got the chance to establish a network with some experts and institutions which are really [renowned] and inspiring."}

- Jeeban Panthi, participant

\section{The conference shall remain special for me as a means for gaining new skills and a great exposure to the international community.}

- Mohit Prakash Mohanty, participant

multiple scales, and gain perspective on policy-making implications.

Grant funds were assigned based on financial need, scientific background and scientific quality/relevance/ impact of submitted abstracts. Priority was given primarily to early-career scientists, post-graduate students and researchers who received their highest degree in 2011 or later, and scientists from emerging and developing economies. The second priority was given to students pursuing their graduate studies (MSc, $\mathrm{PhD}$ ).

About 120 applications were received, 46 of which were from the Asia-Pacific region. A review process to evaluate these applications was carried out by a panel of experts representing the CORDEX domains and areas of expertise within the CORDEX community. From the total pool of applicants, the evaluation panel identified 90 eligible applications. Thirty-five of the selected recipients were from the Asia-Pacific region and fourteen were supported directly with the grant from APN.

As part of the conference activities, a poster presentation competition was organized for students and

\section{RESULTS AND DISCUSSION}

The conference brought together the international community of regional climate scientists and stakeholders with a particular emphasis on issues of added value, vulnerability, impact and assessment and the current and future use of regional climate information and CORDEX results. The first day featured an Opening Session with the participation of Jan Olsson, the Swedish Environment Ambassador, where a general discussion on challenges related to climate and climate change was discussed. In the following Plenary Session on CORDEX achievements and lessons learned, the future of CORDEX was the main issue. Two of the speakers were IPCC WGI and WGII co-chairs, who talked about IPCC needs and the best use of CORDEX. Distillation of climate information and how to communicate tailored messages at appropriate scales to users was a recurring theme during the entire conference period.

The following days were organized into four thematic parallel sessions: benefits of downscaling, includ- 
ing added value and distillation issues; frontier downscaling tools, including human-climate interactions and empirical-statistical downscaling; impacts and applications, including extremes, coupled systems and the path from observations to models to applications; and domain-specific and cross-domain issues.

The final day started with the CORDEX co-chairs William Gutowski and Filippo Giorgi summarizing the status of CORDEX. There are several areas of progress: the CORDEX community worldwide continues to advance scientific understanding of regional climate and regional downscaling; the IPCC has a growing demand for information for regions; the interface between regional climate science and climate services needs further exploration for optimum use of climate research and experience; the added value of regional downscaling has been demonstrated and needs to be further communicated. As part of this progress, a set of coordinated CORDEX experiments that are expected to fill gaps and inhomogeneities within the CORDEX framework are being planned as a basis for further CORDEX work and as an input to the 6th assessment report of the IPCC.

Some issues to address within regional climate research/modelling also emerged. These include a shortage of observations and risk analyses; the benefits of higher resolution versus computational costs; how to coordinate modelling/modellers; the potential loss of information when averaging over ensembles of simulations, which smooths results; the distillation of climate information from data; and interaction and communication with users and stakeholders. Although CORDEX has contributed vastly to the development and production of regional climate data and information, there are still gaps in regional climate downscaling -both knowledge gaps and coverage gaps. To refine and add further to existing information, further development of models, infrastructure, tools and knowledge exchange are needed. The demand for uncertainty estimates, training and capacity building and more tailored information is continuously increasing. These developments call for more interaction with users. Lurking behind these issues are overarching questions such as: What are the limits of CORDEX as a science program? And when does CORDEX hand off its data and climate information to climate services organizations?

This four-day conference clearly demonstrated, through the broad international presence of speakers and poster presenters, the vast achievements of CORDEX and its relevance to VIA communities. CORDEX is a global framework, where scientists around the world cooperate to advance and coordinate climate science and application of regional climate downscaling. This has led to common protocols in the development of both high-resolution
Regional Climate Model (RCM) and Empirical-Statistical Downscaling (ESD) projections, the intercomparison of these projections, and the development of accessible archives of the results.

Conference oral presentations, photos, and videos are accessible from the conference webpage. All plenary sessions were broadcast live via web-streaming, allowing those unable to attend the conference to remotely follow the presentations and discussions. A Twitter account was set up to allow remote questions to be forwarded to the speakers and audience in real-time. Poster sessions during two of the science days facilitated interaction amongst the participants, especially between students, early-career scientists (ECS) and senior researchers.

The programme also featured a special CORDEX-Asia and Australasia session "Regional monsoon hydrological cycle over Asia and Australasia", chaired by J. Sanjay, F. Tangang and J. Evans.

A special event for students and ECS' was organized to promote networking and mentoring for those beginning a career in regional climate research. The focus of this event was on science communication-or, as Asher Minns expressed it, "How you are heard instead of what you are saying". The students, ECS' and senior participants had the opportunity to actively participate and share thoughts and ideas and were invited to discuss and try to explain to their neighbours what their research is about in a simple and non-technical way. After the initial presentation and discussion, four early career scientists presented their experiences of science communication and gave suggestions on how to improve communication. Finally, a discussion on communication-related topics, including miscommunication and ECS communication opportunities followed.

The ECS' funded by APN participated actively at the ICRC-CORDEX conference during the poster sessions, oral presentations and at the early-career scientist sideevent. The poster sessions provided a great opportunity for ECS' to showcase and discuss their own research and acquire new ideas, through engagement with other participants.

A few APN-funded early-career scientists were provided with the opportunity to give an oral presentation during parallel and plenary sessions. The conference also offered early-career scientists an opportunity to talk with their peers and senior scientists, resulting in a great expansion of their network internationally.

\section{CONCLUSION}

Our firm belief and conviction is that the conference was a big success in achieving the objectives to promote the CORDEX vision to advance and coordinate the science 
and application of regional climate downscaling as well as the specific conference objectives. For instance, conference activities included demonstrating and sharing tools, knowledge, and methods for capacity development, sharing best practices and fostering discussions on communication with users and stakeholders. The conference also showcased high-resolution climate information and its applications to vulnerability, impacts, and adaptation by the full spectrum of potential end users of regional climate information. All this would not have been possible without the financial support from several contributors, among them APN. The conference also had good international visibility and, as witnessed by many participants, met well the goals of networking and research capacity development in all domains.

In addition to the students and early career scientists sponsored by APN, WCRP and SMHI sponsored a number of senior scientists from the Asia-Pacific region who greatly contributed to the success of the conference. Scientists and experts from the Asia-Pacific region gave oral presentations, displayed posters and participated in side events and workshops.

The breadth and depth of oral and poster presentations illustrated the relevance of and need for CORDEX on the climate change agenda. CORDEX contributions to impacts, vulnerability and adaptation applications in areas such as the WCRP Grand Challenges, where, for instance, the Food Basket regions where pointed out, are increasingly demanded as well as direct input to IPCC assessments and special reports.

The CORDEX scientific challenges with the aim to target specific regional fine-scale features will act as guidance for the next CORDEX phase. The statistical downscaling also needs to be more visible under CORDEX and integration of ESD groups has been initiated. As a good example of stimulating ESD activities, the CORDEX-Asia ESD group was established in November 2016 during the 4th workshop on the Southeast Asia Regional Climate Downscaling (SEACLID).

The sharing of information from CORDEX is developing and hopefully, in the future, all will be available on the common platform ESGF.

CORDEX Coordinated Output for Regional Evaluations (CORE) program's design and implementation will be a main task in the coming years. The CORE program would engage a succinctly structured core set of RCMs to downscale a core set of GCMs for each CORDEX domain and for a core set of scenarios. In the future, this could be incrementally enlarged with further models and simulations. The CORE program could potentially produce an atlas-like product that could be useful in many areas, such as IPCC assessments.

In summary this project contributed well to the APN goals to (a) support regional cooperation in global change research on issues particularly relevant to the region; (b) enhance capabilities to participate in global change and sustainability research; (c) support science-based decision-making; (d) strengthen appropriate interactions among scientists and policymakers; and (e) provide scientific input to policy decision-making and scientific knowledge to civil society and the public. More broadly, CORDEX-2016 supported the APN goal to cooperate with other global change and sustainability networks and organizations.

\section{ACKNOWLEDGEMENT}

We would like to acknowledge the Bolin Centre and The Swedish Research Council FORMAS for their tremendous contribution to the success of the conference. We thank the scientific committee of the conference who developed the conference programme and identified speakers and session chairs. We also thank the young scientist volunteers who supported the oral and poster sessions and the expert panels who evaluated abstracts and posters. We acknowledge the in-kind web and logistics support from Catherine Michaut, IPSL. Last but not least, we are truly grateful for the financial support from APN, in particular, and from FORMAS, EUMETSAT, ES, and ECRA that made the participation of more than 300 scientists from 38 countries possible.

This APN grant was implemented by different collaborating institutions: National Institute of Meteorological Sciences, Republic of Korea; the World Climate Research Programme (WCRP), Switzerland; Iowa State University, USA; Universiti Kebangsaan, Malaysia; and the Swedish Meteorological and Hydrological Institution, Sweden.

A final word of gratitude goes to the CORDEX community and all of the participants, who made this conference an enjoyable and memorable event.

\section{REFERENCES}

APN Fourth Strategic Plan (2015-2020), 20pp

Third International Conference on Regional Climate, ICRC-CORDEX 2016, http://www.icrc-cordex2016. org/index.php. 